\title{
Degradation of myofibrillar proteins and inadequate antioxidants in selective muscle wasting of limb girdle muscular dystrophy
}

\author{
Rajakumar Dhanarajan, Anilkumar B Patil \\ Mathew Alexander, Geeta Chacko, Anna Oommen
}

\begin{abstract}
Introduction: An unexplained feature of inherited muscular dystrophies is the wasting of selective muscle. Transcriptional signatures that differ between muscles may contribute to selective muscle wasting of muscular dystrophies. Biochemical signaling pathways involved in selective wasting have not been studied. Case Report: This study examined signaling mechanisms that stimulate protein degradation, which may govern selective muscle wasting, in a patient with Miyoshi myopathy. Oxidative stress, nitric oxide signaling and protein degradation through the
\end{abstract}

Rajakumar Dhanarajan', Anilkumar B Patil ${ }^{2}$ Mathew Alexander ${ }^{3}$ Geeta Chacko ${ }^{4}$, Anna Oommen ${ }^{5}$

Affiliations: ${ }^{1}$ Senior Research Fellow, Section of Neurochemistry, Department of Neurological Sciences, Christian Medical College, Vellore, Tamilnadu, India; ${ }^{2}$ Assistant Professor, Section of Neurology, Department of Neurological Sciences, Christian Medical College, Vellore, Tamilnadu, India; ${ }^{3}$ Professor, Section of Neurology, Department of Neurological Sciences, Christian Medical College, Vellore, Tamilnadu, India; ${ }^{4}$ Professor, Section of Neuropathology, Department of Neurological Sciences, Christian Medical College, Vellore, Tamilnadu, India.; ${ }^{5}$ Senior Scientist Grade-I, Section of Neurochemistry, Department of Neurological Sciences, Christian Medical College, Vellore, Tamilnadu, India.

Corresponding Author: Dr. R Dhanarajan, Neurochemistry Laboratory, Department of Neurological Sciences, Christian Medical College, Vellore 632 004, India; Phone: 91-9790570526; Fax: 91-416-2232035 Email: dhanurajan@hotmail.com

Received: 02 February 2011

Accepted: 26 March 2011

Published: 30 June 2011 ubiquitin proteasome pathway were studied in relatively spared hamstring and wasted gastrocnemius muscle of the patient and in control muscle. Oxidative stress occurred in spared and wasted Miyoshi myopathic muscle. A strong anti-oxidant response was observed in spared muscle. Tyrosine nitration of $56 \mathrm{kDa}$ protein(s) was 2.3 and 5 fold higher in spared and wasted muscles respectively compared to normal. Nitrocysteinylated proteins were comparable between spared hamstring and normal muscle but reduced $35 \%$ in gastrocnemius muscle compared to normal. Ubiquitinylated proteins were increased 2.6 fold in the hamstring muscle and 1.6 fold in the gastrocnemius muscle compared to normal. The protein content of the hamstring and gastrocnemius muscles was reduced $43 \%$ and $37 \%$ respectively compared to normal. Myosin heavy chain and actin levels were normal in hamstring muscle but reduced nearly four fold in gastrocnemius muscle compared to normal. Conclusion: Oxidative and nitrosative stress and loss of actin and myosin were associated with selective muscle wasting of Miyoshi myopathy. A strong anti-oxidant response that protects myofibrillar proteins against degradation may spare muscle in Miyoshi myopathy.

Keywords: Actin, Miyoshi myopathy, Myosin, Nitric oxide, Ubiquitin-proteasome pathway

$* * * * * * * * *$

Dhanarajan R, Patil AB, Alexander M, Chacko G, Oommen A. Degradation of myofibrillar proteins and inadequate antioxidants in selective muscle wasting of limb girdle muscular dystrophy. International Journal of Case Reports and Images 2011;2(6):6-11. 
buffered formalin, processed routinely and $4 \mu$ sections of paraffin-embedded tissue stained with haematoxylin and eosin (H\&E).

\section{INTRODUCTION}

An intriguing feature of muscular dystrophies is the involvement of selective tissue with disease progression despite a common mutation in all tissues. Transcriptional signatures that differ between muscles suggest that specific signaling pathways may be associated with selective muscle wasting of muscular dystrophies [1]. The proteomics of these signaling pathways have been not explored in detail.

Limb girdle muscular dystrophies (LGMD) are among the most common muscular dystrophies which target the limb girdle musculature. Dysferlinopathies, autosomal recessive LGMD, are due to absence or reduction of the muscle membrane protein, dysferlin [2]. A case of dysferlinopathy is presented to highlight preferential loss of specific proteins in selectivity of genetic disease. The major muscle proteins myosin and actin, oxidative and nitrosative stress that activate protein degradation and the ubiquitin proteasome protein-degrading pathway, were assessed in relatively spared hamstring muscle and wasted gastrocnemius muscle of a patient with Miyoshi myopathy, to determine their role in selective muscle dystrophy.

\section{CASE REPORT}

The patient was a 22-year-old male who presented with a 4-year history of pain in his calf, thigh and gluteal muscles while walking. He developed thinning and weakness of calf muscles and later of the thigh muscles. He is born of a non-consangenious union and has no family history.

Neurological examination revealed marked bilateral wasting of the calf muscles, foot muscles, hamstring and quadriceps. Lower limbs had marked weakness of the plantar flexion of the ankle (MRC 3/5) and the other groups of muscles had an MRC $4 / 5$. Deep tendon reflexes were absent at the ankles. He had a waddling gait and could not walk on his toes. His serum creatine kinase was 9431 units/litre and the EMG was supportive of a myopathic process. He underwent a muscle biopsy of his right gastrocnemius muscle. Six months later MR imaging of the lower limbs led to a muscle biopsy of the left hamstring muscle.

The muscle biopsies were subject to histology, immunohistochemistry and western blot analysis. Normal muscles obtained from five patients undergoing surgery for clubfoot correction served as controls. All muscle samples were obtained with informed consent.

\section{Methods}

Histology - Muscles were fixed in 10\% neutral

SDS-polyacrylamide gel electrophoresis (SDS-PAGE) - Protein was estimated as non-collagen protein by the method of Lowry, subsequent to alkaline hydrolysis of muscle, to exclude misinterpretation of fibrous proteins as muscle proteins. Muscles were homogenized in 19 volumes $0.125 \mathrm{M}$ Tris/Hcl pH 7.6 containing $10 \%$ glycerol, $10 \% \mathrm{SDS}, 4 \mathrm{M}$ urea, $0.1 \mathrm{M}$ EDTA, $10 \% \quad \beta$-mercaptoethanol and $0.05 \%$

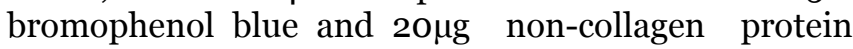
subject to reducing SDS-PAGE (3.5-12\% gels). Proteins were visualized on gels stained with Coomassie brilliant blue-R 250. To normalize for protein loading the ratio of actin/ myosin heavy chain intensity to total protein intensity of each lane was considered.

Western blots - Proteins were electrotransferred to polyvinylidene fluoride membranes for 1 hour $\left(80 \mathrm{O} / 4^{\circ} \mathrm{C}\right)$ following electrophoresis of $50-100 \mu \mathrm{g}$ noncollagen protein and separate blots were probed with primary antibodies to dysferlin, calpain-3, nitrotyrosine, nitrocysteine, NF- $\mathrm{KBp} 65$, ubiquitin or glyceraldehyde phosphate dehydrogenase (GAPDH) and developed by the streptavidin peroxidase method. Post transferred gels were stained with Coomassie brilliant blue-R 250. Densitometric image analysis of gels and blots was performed with software developed in-house that correlated with Bio-Rad Quantity One Quantitation software version $4(\mathrm{r}=0.8)$.

Oxidative and nitrosative stress parameters - Muscles were homogenized in 10 volumes of specific assay buffers and assayed for lipid peroxidation by the thiobarbituric acid reaction for malondialdehyde, protein thiols by their reaction with 5'5'dithiobis-2-nitrobenzoic acid (DTNB), reduced glutathione (GSH) by the colorimetric method of Ellman and catalase by the breakdown of $\mathrm{H}_{2} \mathrm{O}_{2}$ at $240 n m$. Nitrate, the stable end product of nitric oxide (NO), was reduced to nitrite with copper-cadmium alloy and assayed in muscle homogenates by the Griess reaction.

\section{Diagnosis}

Although mutation analysis is the gold standard for diagnosis of dysferlinopathy, clinical features specific to dysferlinopathy with immune blots negative for dysferlin are considered diagnostically adequate and comparable to mutational analysis [3]. The patient in this study was diagnosed as Miyoshi myopathy based on clinical findings, muscle histopathology, immunohistochemistry and western blots negative for dysferlin. 


\section{Results}

Histopathology, immunohistochemistry and western blots - The gastrocnemius muscle showed extensive replacement by fibrocollagenous tissue (Figure 1). Histopathology of the left hamstring muscle revealed preserved architecture with myopathic features (Figure 1). Immunohistochemistry indicated the presence of dystrophin and $\alpha$ - sarcoglycans in both muscles (data not shown). On immune blots, dysferlin was absent (Figure 2) and calpain 3 was present in hamstring and gastrocnemius muscles of the patient (data not shown).

Muscle proteins - Protein content of hamstring and gastrocnemius muscles were reduced $43 \%$ and $37 \%$ respectively, compared to normal muscle (Table 1). Myosin heavy chain and actin levels were slightly decreased ( 0.1 fold) in the hamstring muscle but reduced 4.2 and 3.7 fold respectively, in the gastrocnemius muscle as determined from SDS-PAGE protein profiles (Figure 3A) (Table 1). Ubiquitinylated proteins were increased 2.6 fold in hamstring muscle and 1.6 fold in gastrocnemius muscle compared to normal muscle (Figure 3B) (Table 1). NF-kB p65 protein increased 6.6 fold in hamstring and 11.5 fold in gastrocnemius muscle compared to normal muscle (Table 1).

Oxidative and nitrosative stress - Lipid peroxidation, protein thiols and protein carbonyls were 3.5, 2.5 and 16 fold higher in hamstring muscle compared to normal muscle. Their levels in the gastrocnemius muscle were less than 1.8 fold higher than normal (Table 1). Nitrite levels were elevated three fold in hamstring and four fold in gastrocnemius muscle compared to normal (Table 1). Tyrosine nitration of proteins in the range of $56 \mathrm{kDa}$ was 2.3 fold and five fold higher in the hamstring and gastrocnemius muscles respectively compared to normal muscle (Figure $3 \mathrm{C}$ ) (Table 1). S-nitrosylation of cysteine groups was comparable between proteins of hamstring and normal muscle (Figure 3D). Their levels were $35 \%$ less in the gastrocnemius muscle compared to normal (Figure 3D) (Table 1).

Antioxidants in muscles - Reduced glutathione was elevated three fold in the hamstring muscle and decreased three fold in the gastrocnemius muscle compared to normal (Table 1). Catalase was elevated eight fold in the hamstring muscle and five fold in the gastrocnemius muscle compared to normal (Table 1).

\section{DISCUSSION}

The arguments in this study for suggesting mechanisms of selective and preferential loss of the gastrocnemius muscle in Miyoshi myopathy are based on the earlier severe wasting of this muscle compared to the hamstring muscle that remains preserved even
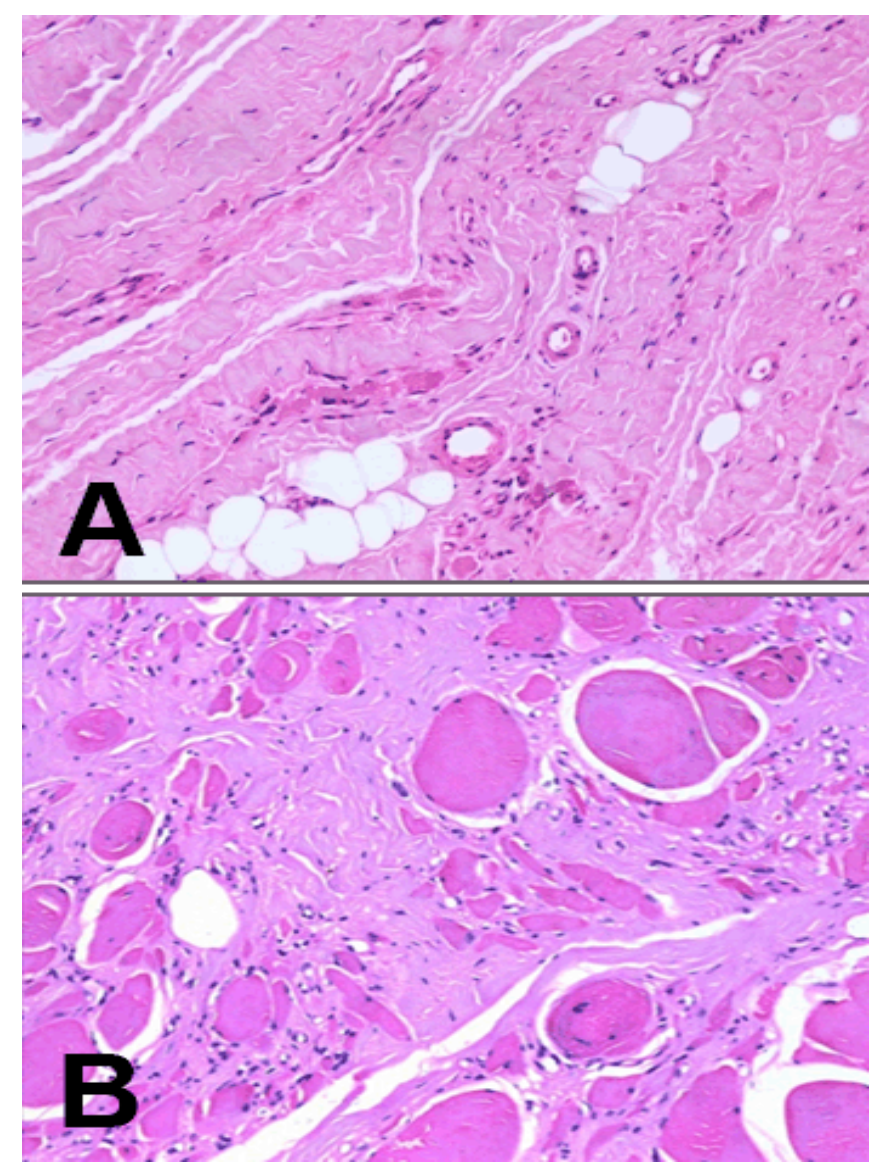

Figure 1: Photomicrographs of A) wasted gastrocnemius muscle illustrating the end stage muscle with marked fibrosis and replacement by adipose tissue, B) Photomicrographs of hamstring muscle, illustrating skeletal muscle with myopathic features.(H\&E x2OO).

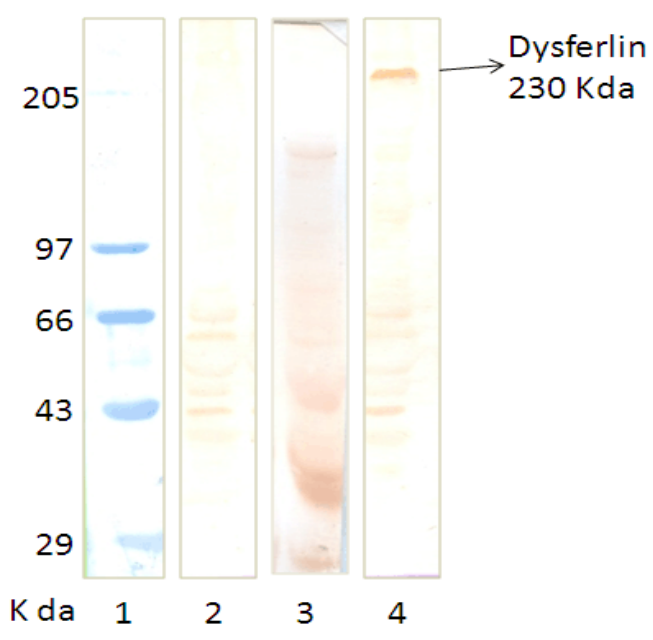

Figure 2: Western blot for Dysferlin. 10oug non collagen protein of each muscle was subjected to SDS-PAGE (3.5$12 \%)$, blotting was done as given in methods. Blots were probed with anti dysferlin antibodies. Molecular weight marker (lane 1), hamstring muscle (lane 2), gastrocnemius muscle (lane 3), control muscle (lane 4). 
Table 1: Protein, oxidant, anti-oxidant and nitric oxide profiles of Miyoshi myopathy muscles.

\begin{tabular}{|c|c|c|c|c|}
\hline Parameter & Unit & $\begin{array}{l}\text { Control } \\
\text { Muscle }\end{array}$ & $\begin{array}{l}\text { Hamstring } \\
\text { muscle }\end{array}$ & $\begin{array}{l}\text { Gastrocnemius } \\
\text { muscle }\end{array}$ \\
\hline \multicolumn{5}{|l|}{ Protein status } \\
\hline Non-collagen protein & $\mathrm{mg} / \mathrm{g}$ protein & $254 \pm 56$ & 145 & 160 \\
\hline Ubiquitinylated proteins & Intensity (AU) & $1996 \pm 806$ & 5135 & 3211 \\
\hline NF- $\kappa \mathrm{B}$ p65/GAPDH & Band intensity ratio & $0.122 \pm 0.08$ & 0.8 & 1.4 \\
\hline \multicolumn{5}{|l|}{ Myofibrillar proteins } \\
\hline $\begin{array}{l}\text { Myosin Heavy Chain (MI } \\
\text { All muscle proteins }\end{array}$ & Band intensity ratio & $0.063 \pm 0.007$ & 0.055 & 0.015 \\
\hline Actin/ All muscle proteins & Band intensity ratio & $0.062 \pm 0.006$ & 0.055 & 0.017 \\
\hline \multicolumn{5}{|l|}{ ROS } \\
\hline Lipid peroxidation & TBARS nmoles/g NCP & $498 \pm 99$ & 1724 & 750 \\
\hline Protein thiols & DTNB nmoles/mg protein & $21.8 \pm 3.8$ & 55 & 40 \\
\hline Protein carbonyl & DNPH nmoles/g protein & $0.19 \pm 0.07$ & 3.1 & 0.34 \\
\hline Nitrite & nmoles/mg protein & $10.1 \pm 1.1$ & 34 & 45 \\
\hline Nitrotyrosine & Band intensity (AU) & $53.0 \pm 16.0$ & 125 & 263 \\
\hline Nitrocysteine & Band intensity (AU) & $207 \pm 90.6$ & 313 & 136 \\
\hline \multicolumn{5}{|l|}{ Antioxidants } \\
\hline GSH & $\mu \mathrm{M} / \mathrm{g}$ muscle & $3.4 \pm 1.7$ & 10.3 & 1.0 \\
\hline Catalase & $\mathrm{U} / \mathrm{mg}$ protein & $30 \pm 10.8$ & 234 & 156 \\
\hline
\end{tabular}

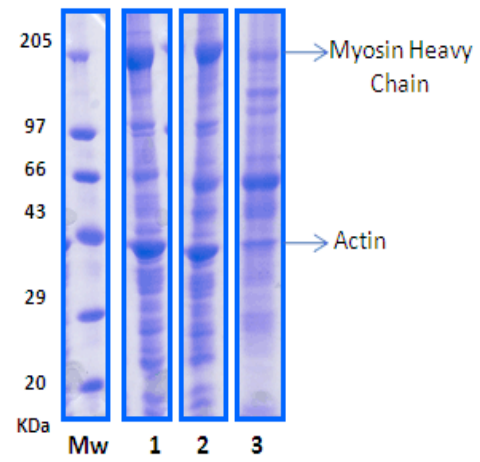

A

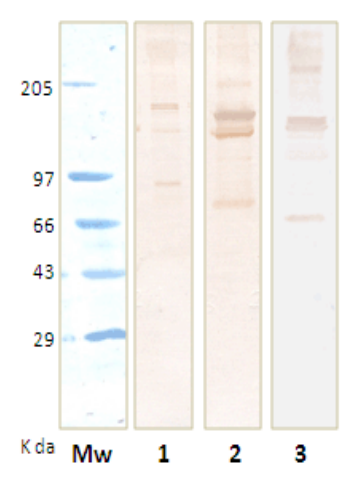

B

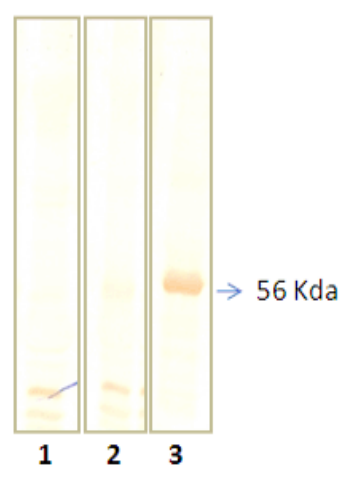

C

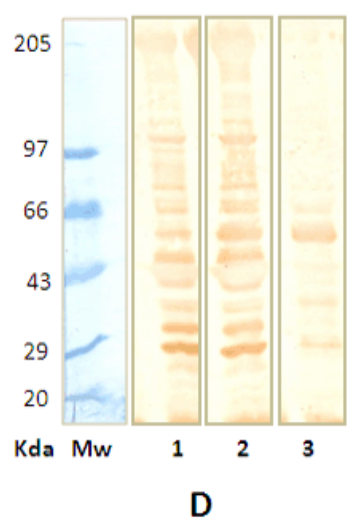

D

Figure 3: A) SDS - PAGE of muscle proteins: 20 ug of non collagen protein of each muscle subjected to SDS-PAGE (3.5-12\%) and the gels stained with commassie briliant blue R-250. B) Western blot of Ubiquitinylated muscle proteins: 10oug non collagen protein of each muscle was subjected to SDS-PAGE (3.5-12\%), blotting was done as given in methods. Blots were probed with anti ubiquitin antibodies, Immune blots of C) nitrotyrosinylated and D) S-nitroso cysteine proteins. Muscle proteins: 100 ug non collagen protein of each muscle was subjected to SDS-PAGE (3.5-12\%), blotting was done as given in methods. Blots were probed with anti nitrocysteine and anti nitrotyrosine antibodies. Molecular weight marker (lane 1), Control muscle (lane 2), Hamstring muscle (lane 3), Gastrocnemius muscle (lane 4) 
six months later. The absence of dysferlin was associated with significant protein loss by degradation through the ubiquitin proteasome system in both muscles. The nature of the lost proteins were different and this maybe important in the pathogenesis of Miyoshi myopathy. Loss of actin and myosin in the gastrocnemius muscle resulting in a $40 \%$ decrease in the myosin to actin ratio may account for weakness of this muscle in Miyoshi myopathy.

Muscles with the capacity to protect their major myofibrillar proteins from degradation maybe spared in Miyoshi myopathy, as noted in the hamstring muscle, where loss may mainly be of sarcoplasmic and extracellular proteins.

Mediators of intracellular signaling that regulate protein degradation include oxidative and nitrosative stress $[4,5,6]$. Absence of dysferlin appears to induce oxidative stress in both spared hamstring and affected gastrocnemius muscles. The ability to mount a strong anti-oxidant defense in the spared muscle but only a weak response in the wasted muscle suggests that guarding against oxidative damage is important to spare muscle in Miyoshi myopathy.

In the oxidative environment of the muscle, $\mathrm{NO}$ can convert to reactive nitrogen species which can modify proteins and activate different signaling pathways including those that act through NF- $\mathrm{BB}$ [7]. Posttranslational modifications induced by $\mathrm{NO}$, of tyrosine nitration and S-nitrocysteinylation, can be protective or induce protein degradation and cell death [8]. The NO profiles of spared and affected muscles of Miyoshi myopathy suggest a role for NO in committing cells to death. In muscles that are spared, although NO is elevated, the NO signature resembles that of normal muscle with respect to nitro-cysteinylated proteins. Tyrosine nitration of protein(s) of $56 \mathrm{kDa}$ is minor. Elevated levels of GSH in this muscle may scavenge NO and maintain the normal NO profile. In contrast predominant tyrosine nitration of $56 \mathrm{kDa}$ protein(s) with concomitant reduction of nitro-cysteinylated proteins and increased NF- $\mathrm{KB}$ p65 in wasted muscle may underlie signaling pathways that direct selective muscle wasting of Miyoshi myopathy. Similar findings are noted in disuse-induced atrophy. In rats subject to space flights or hind limb suspension, where the gastrocnemius muscle is selectively wasted, preferential wasting of myosin heavy chain, increased lipid peroxidation, decreased reduced glutathione and increased muscle protein polyubiquitinylation are also reported $[9,10]$.

\section{CONCLUSION}

Oxidative and nitrosative stress that lead to nitration of tyrosine on protein(s) of $56 \mathrm{kDa}$ may signal degradation of the actinomyosin complex and result in weakness. A strong antioxidant defense that guards against loss of contractile proteins may spare the muscle.
$* * * * * * * * *$

\section{Acknowledgements}

R. Dhanarajan is supported by a senior research fellowship of the Indian Council of Medical Research (Project No 5/4 -5/2/Neuro/2008).

\section{Author Contributions}

Rajakumar Dhanarajan - Conception and design, Acquisition of data, Analysis and interpretation of data, Drafting the article, Critical revision of the article, Final approval of the version to be published

Anilkumar B Patil - Conception and design, Drafting the article, Critical revision of the article, Final approval of the version to be published

Mathew Alexader - Conception and design, Drafting the article, Critical revision of the article, Final approval of the version to be published

Geeta Chacko - Conception and design, Drafting the article, Critical revision of the article, Final approval of the version to be published

Anna Oommen - Conception and design, Acquisition of data, Analysis and interpretation of data, Drafting the article, Critical revision of the article, Final approval of the version to be published

\section{Guarantor}

The corresponding author is the guarantor of submission.

\section{Conflict of Interest}

Authors declare no conflict of interest.

\section{Copyright}

(C) Rajakumar Dhanarajan et al. 2011; This article is distributed under the terms of Creative Commons attribution 3.0 License which permits unrestricted use, distribution and reproduction in any means provided the original authors and original publisher are properly credited. (Please see www.ijcasereportsandimages.com /copyright-policy.php for more information.)

\section{REFERENCES}

1. von der Hagen M, Laval SH, Cree LM, Haldane F, Pocock M, Wappler I, et al. The differential gene expression profiles of proximal and distal muscle groups are altered in pre-pathological dysferlindeficient mice. Neuromuscul Disord. 2005;15:86377.

2. Weiler T, Bashir R, Anderson LV, Davison K, Moss JA, Britton S, et al. Identical mutation in patients with limb girdle muscular dystrophy type $2 \mathrm{~B}$ or Miyoshi myopathy suggests a role for modifier gene(s). Hum Mol Genet. 1999;8:871-7.

3. Sáenz A, Leturcq F, Cobo AM, Poza JJ, Ferrer X, Otaegui D, et al. LGMD2A: genotype-phenotype correlations based on a large mutational survey on the calpain 3 gene. Brain. 2005;128:732-42. 
4. Tidball JG, Wehling-Henricks M. The role of free radicals in the pathophysiology of muscular dystrophy. J Appl Physiol. 2007;102:1677-86.

5. Ragusa RJ, Chow CK, Porter JD. Oxidative stress as a potential pathogenic mechanism in an animal model of Duchenne muscular dystrophy. Neuromuscul Disord. 1997;7:379-86.

6. Messina S, Altavilla D, Aguennouz M, Seminara P, Minutoli L, Monici MC, et al. Lipid peroxidation inhibition blunts nuclear factor-kappaB activation, reduces skeletal muscle degeneration, and enhances muscle function in mdx mice. Am $\mathrm{J}$ Pathol. 2006;168:918-26.

7. Marshall HE, Merchant K, Stamler JS. Nitrosation and oxidation in the regulation of gene expression. FASEB J. 2000;14:1889-1900.

8. Callahan LA, Stofan DA, Szweda LI, Nethery DE, Supinski GS. Free radicals alter maximal diaphragmatic mitochondrial oxygen consumption in endotoxin-induced sepsis. Free Radic Biol Med. 2001;30:129-38.

9. Ikemoto M, Nikawa T, Kano M, Hirasaka K, Kitano $\mathrm{T}$, Watanabe $\mathrm{C}$, et al. Cysteine supplementation prevents unweighting-induced ubiquitination in association with redox regulation in rat skeletal muscle. Biol Chem. 2002;383:715-21.

10. Ikemoto M, Nikawa $T$, Takeda S, Watanabe C, Kitano T, Baldwin KM, et al. Space shuttle flight (STS-90) enhances degradation of rat myosin heavy chain in association with activation of ubiquitinproteasome pathway. FASEB J. 2001;15:1279-81. 